\title{
Hygroscopic growth of sub-micrometer and one-micrometer aerosol particles measured during ACE-Asia
}

\author{
A. Massling ${ }^{1}$, S. Leinert ${ }^{2}$, A. Wiedensohler ${ }^{1}$, and D. Covert ${ }^{3}$ \\ ${ }^{1}$ Leibniz-Institute for Tropospheric Research, Permoserstr. 15, 04318 Leipzig, Germany \\ ${ }^{2}$ Environmental Protection Agency, Richview, Clonskeagh Road, Dublin 14, Ireland \\ ${ }^{3}$ Department of Atmospheric Sciences, University of Washington, Box 354235, Seattle, WA 98195-4235, USA
}

Received: 20 October 2006 - Published in Atmos. Chem. Phys. Discuss.: 28 November 2006

Revised: 3 May 2007 - Accepted: 30 May 2007 - Published: 25 June 2007

\begin{abstract}
Hygroscopic properties of aerosol particles in the sub-micrometer and one-micrometer size ranges were measured during the ACE-Asia study (Aerosol Characterization Experiment-Asia) in spring 2001. The measurements took place off the coasts of Japan, Korea, and China. All instruments contributing to this study were deployed in a container on the forward deck of the NOAA Research Vessel Ronald H. Brown. Air masses with primarily marine influence and air masses from the Asian continent affected by both anthropogenic sources and by the transport of desert dust aerosol were encountered during the cruise.

Results showed very different hygroscopic behavior in the sub-micrometer size range compared to the one-micrometer size range. In general, for all continentally influenced air masses, the one-micrometer particle population was characterized by two different particle groups - a nearly hydrophobic fraction with growth factors around 1.0 representative of dust particles and a sea salt fraction with hygroscopic growth factors around 2.0. The number fraction of dust particles was generally about $60 \%$ independent of long-range air mass origin.
\end{abstract}

For sub-micrometer particles, a dominant, more hygroscopic particle fraction with growth factors between 1.5 and 1.9 (depending on dry particle size) consistent with ammonium sulfate or non-neutralized sulfates as major component was always found. In marine air masses and for larger sizes within the sub-micrometer range ( $D p=250$ and $350 \mathrm{~nm})$, a sea salt fraction with growth factors between 2.0 and 2.1 was also observed. For all other air masses, the more hygroscopic particle fraction in the sub-micrometer size range was mostly accompanied by a less hygroscopic particle fraction with growth factors between 1.20 and 1.55 depending on both the continental sources and the dry particle size. Number fractions of this particle group varied between 4 and 39\%

Correspondence to: A. Massling

(massling@ tropos.de) depending on dry particle size and air mass type. Nearly hydrophobic particles indicating dust particles in the submicrometer size regime were only found for particles with $D p=250$ and $350 \mathrm{~nm}$ during a time period when the aerosol was influenced by transport from Asian desert regions.

\section{Introduction}

Aerosol particles play an important role in the atmosphere, because they influence the radiative budget of the earth directly by scattering and absorbing the incoming sunlight and indirectly by serving as cloud condensation nuclei for the formation of fog and cloud droplets (Twomey, 1977). One of the important aerosol properties that controls the magnitude of this effect is their hygroscopicity. Depending on the chemical composition, aerosol particles can take up large amounts of water compared to their dry state as relative humidity (RH) increases above $60 \%$ and thus radically increase their size and change their optical properties (Ogren and Charlson, 1992). The hygroscopic behavior of aerosol particles also influences cloud formation processes and the resulting droplet size distribution and thus the cloud albedo. A change in the cloud albedo due to large-scale anthropogenic activities in Asia may significantly affect the regional climate. Hygroscopic growth data for atmospheric aerosols are needed to simulate microphysical aerosol properties such as number size distributions and scattering and absorption coefficients at ambient conditions in meso-scale and global radiation transfer models.

In Asia and especially in China, high number and mass concentrations of aerosol particles together with water uptake at high RHs lead to reduced visibilities. Several studies in the past have shown that a decrease of visibility is correlated with an increase of aerosol number concentration or aerosol mass (Noll et al., 1968; Charlson, 1969). One of the original reasons to study hygroscopic properties of aerosol

Published by Copernicus Publications on behalf of the European Geosciences Union. 


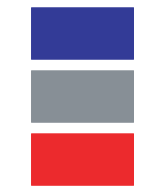

Marine air mass

Polluted by Korea and Japan

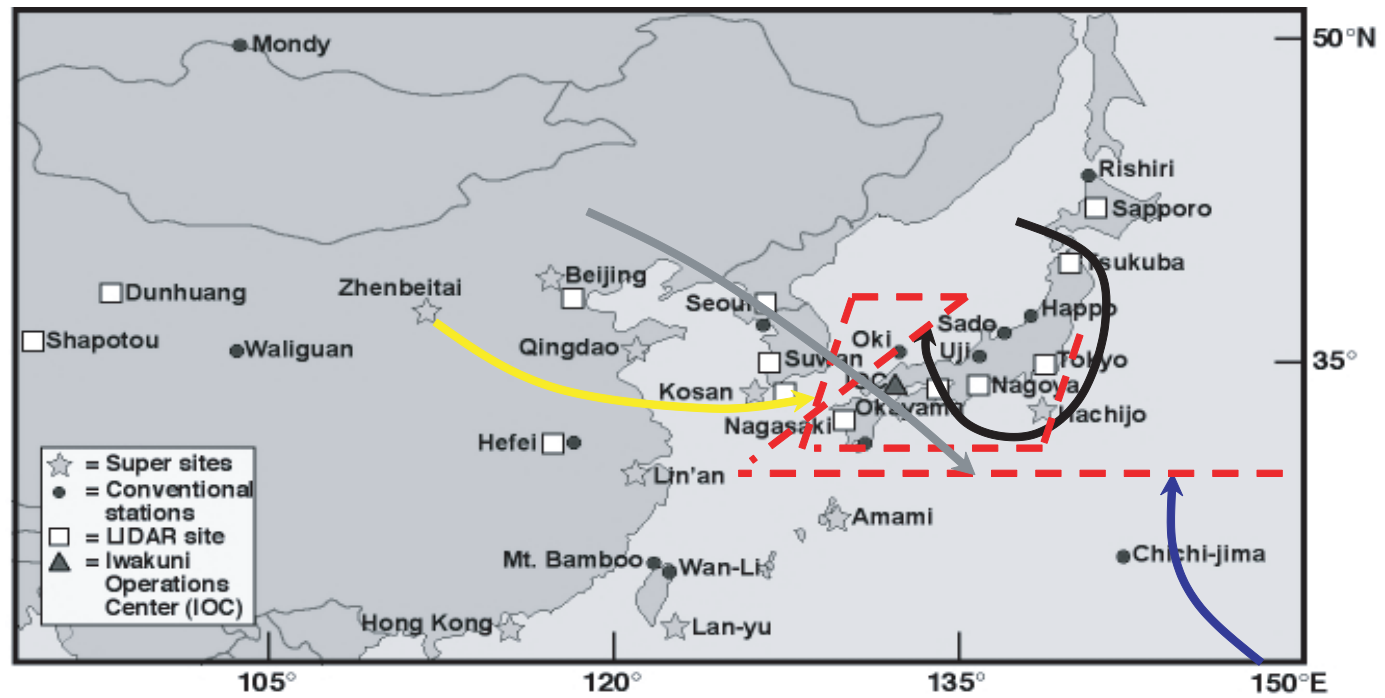

Fig. 1. Map of different air masses observed during the ACE-Asia cruise.

particles was the dependence of visibility on the relative humidity (Kasten, 1968). It has been shown that the visibility continuously decreases with increasing relative humidity (Tsay et al., 1991; Horvath, 1995).

In addition to effects of aerosol particles on global climate and visibility, particles have been implicated as being detrimental to human health (Peters et al., 1997a, b; Cooney, 1998; Pope and Dockery, 1999). Investigations have shown that the hygroscopic properties of aerosol particles play an important role in this context (Ferron et al., 1998).

Hygroscopic properties of aerosol particles were investigated in marine environments in several field studies in the last ten years (e.g., Berg et al., 1998; Swietlicki et al., 2000; Massling et al., 2003). However, there have been no intensive investigations on this issue characterizing marine air masses, which were affected by Asian dust regions and mega-cities in Japan, Korea, or China. In general, the knowledge of emissions in the Eastern Asian regions is limited. In Southeastern Asia, in countries like Indonesia the industrialization is rapidly increasing and their contribution to environmental pollution is not well known.

In this investigation, the common Hygroscopicity-Tandem Differential Mobility Analyzer technique was used to measure hygroscopic characteristics in the sub-micrometer size range. Particles with initial dry sizes of $D p=50 \mathrm{~nm}$ (hereafter called Aitken mode particles) and $D p=150,250$, and $350 \mathrm{~nm}$ (accumulation mode) were investigated. This technique is usually instrumentally limited to particles less than $400 \mathrm{~nm}$ in dry diameter. In addition, the new Hygroscopicity-
Differential Mobility Analyzer-Aerodynamic Particle Sizer technique was employed to measure hygroscopic properties of one-micrometer particles (coarse mode particles).

The hygroscopic properties of Aitken, accumulation, and coarse modes are compared and discussed. This data set gives a new overview about hygroscopic characteristics of sub-micrometer and one-micrometer aerosol particles having their origin in a region, which has not been intensively investigated up to now and which develops as a major emitter of anthropogenic aerosol.

\section{Experimental}

An H-TDMA-system (Hygroscopicity-Tandem Differential Mobility Analyzer) and an H-DMA-APSsystem (Hygroscopicity-Differential Mobility AnalyzerAerodynamic Particle Sizer) were operated on board the US NOAA Research Vessel Ronald H. Brown (RHB) to measure the hygroscopic growth of sub-micrometer and one-micrometer aerosol particles. The sampling container was located on the deck immediately forward of and below the bridge and adjacent to the other atmospheric chemistry sampling vans (Quinn et al., 2004). Sample air for the measurements was drawn through a $6 \mathrm{~m}$ sample mast above the sampling container. The entrance to the mast was $18 \mathrm{~m}$ above sea level and $30 \mathrm{~m}$ forward of the ship's stack.

During the experiment, air masses containing aerosols from different geographical origins were advected across the 


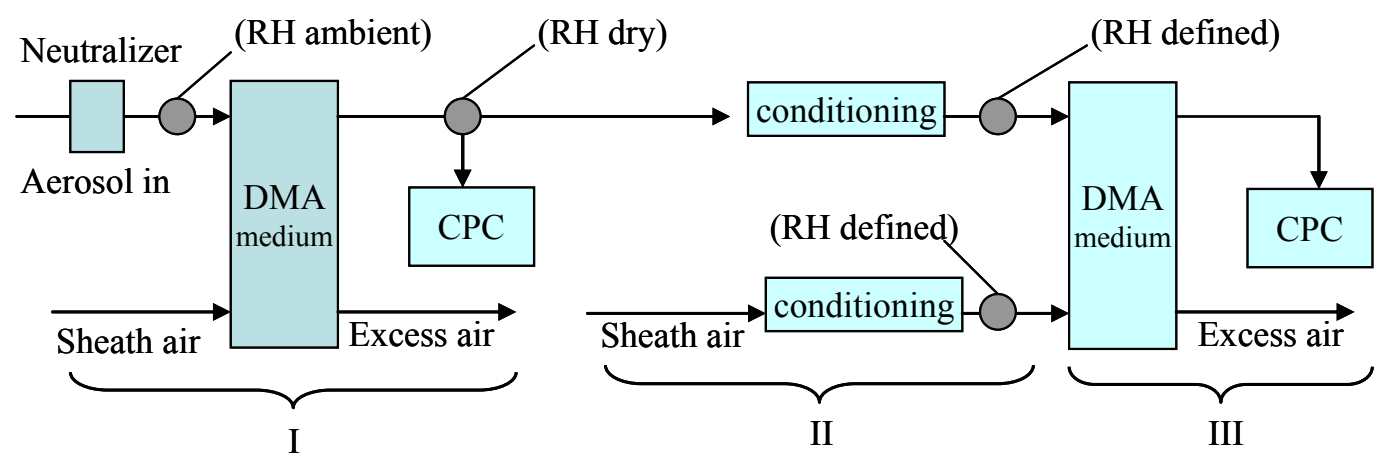

Fig. 2a. Schematic drawing of the H-TDMA system.

Table 1. List of time periods with different air mass origin during ACE-Asia.

\begin{tabular}{lll}
\hline Time period & DOY & Air mass type \\
\hline 1 & $75-84$ & Marine \\
2 & $91-94$ & Polluted Korea/Japan \\
3 & $96.4-99.2$ & Polluted Japan \\
4 & $99.3-100.5$ & Volcano + Polluted \\
5 & $103.4-104.5$ & Dust + Shanghai \\
\hline
\end{tabular}

ship's cruise track and thus different aerosol types were investigated. The H-TDMA was used to measure the hygroscopic characteristics in the sub-micrometer size range for particles with initial dry sizes of $D p=50,150,250$, and $350 \mathrm{~nm}$ in dry diameter at $90 \% \mathrm{RH}$. The H-DMA-APS measured the hygroscopic growth of aerosol particles at $1 \mu \mathrm{m}$ in dry diameter. The combination of both systems yielded growth factors determined at $90 \% \mathrm{RH}$ and information about the mixing state of aerosol particles between $50 \mathrm{~nm}$ and $1 \mu \mathrm{m}$ in dry size.

\subsection{Location and air mass types}

The cruise started on 14 March 2001, in Pearl Harbor, Hawaii, and finished on 20 April 2001, in Yokosuka, Japan. During this time period the ship crossed the western part of the Northern Pacific and then sailed within the coastal waters of Japan, Korea, and China. The study region is illustrated in Fig. 1. The cruise was divided into seven consecutive time periods when air masses representing different aerosol sources and types were encountered (Bates et al., 2004). The geographical origin of the different aerosol sources and air mass types that will be discussed in this work encountered during the cruise, is summarized in Table 1. Five of the seven periods were selected for analysis of hygroscopic properties. At the beginning of the cruise, marine air masses having no land contact for six days were sampled over a period of eleven days. The following time periods were characterized by air mass types which were continentally influenced according to the back-trajectory analysis. These air masses were imprinted in terms of their aerosol chemistry by passing Japan and Korea, or China and crossing mega-cities in these countries or by entraining dust material over different Asian dust regions and volcanic emissions. A more detailed characterization of the observed air masses is discussed in Bates et al. (2004).

\subsection{Instrumentation}

\subsubsection{H-TDMA system (Hygroscopicity-Tandem Differen- tial Mobility Analyzer)}

The H-TDMA-system consists of two Differential Mobility Analyzers (DMA) in series and an aerosol humidifier between them (Liu et al., 1978). Figure 2a shows a schematic of the H-TDMA system. In principle, the H-TDMA can be described as three sections: before entering the first DMA, the aerosol passes through a nafion dryer where the $\mathrm{RH}$ of the aerosol is decreased to $<25 \%$. Then, the aerosol passes through a bipolar charger. Inside the first DMA, the aerosol is instantly dried by the sheath air to a $\mathrm{RH}<5 \%$. The flow containing nearly monodisperse aerosol particles of the selected diameter leaving the DMA is divided into two equal fractions. One part is directed to the first CPC, which measures the particle number concentration leaving the first DMA at the selected particle size (I). The second part of the flow is directed to the aerosol humidifier where it is initially humidified to a defined $\mathrm{RH}>85 \%$ to guarantee that all particles have exceeded the deliquescence point independent of their chemical composition. The particles then are conducted to the inlet of the second DMA. The sheath air of the second DMA is brought to a final defined $\mathrm{RH}$ of $90 \%$ in a separate, second humidifier (II). For further control of the system, the RH in the excess air line is also monitored by a calibrated capacitive sensor. Inside the second DMA, the monodisperse aerosol is exposed to the RH of the sheath air. The equilibrium RH in the second DMA is then close to $90 \%$, because the volume 


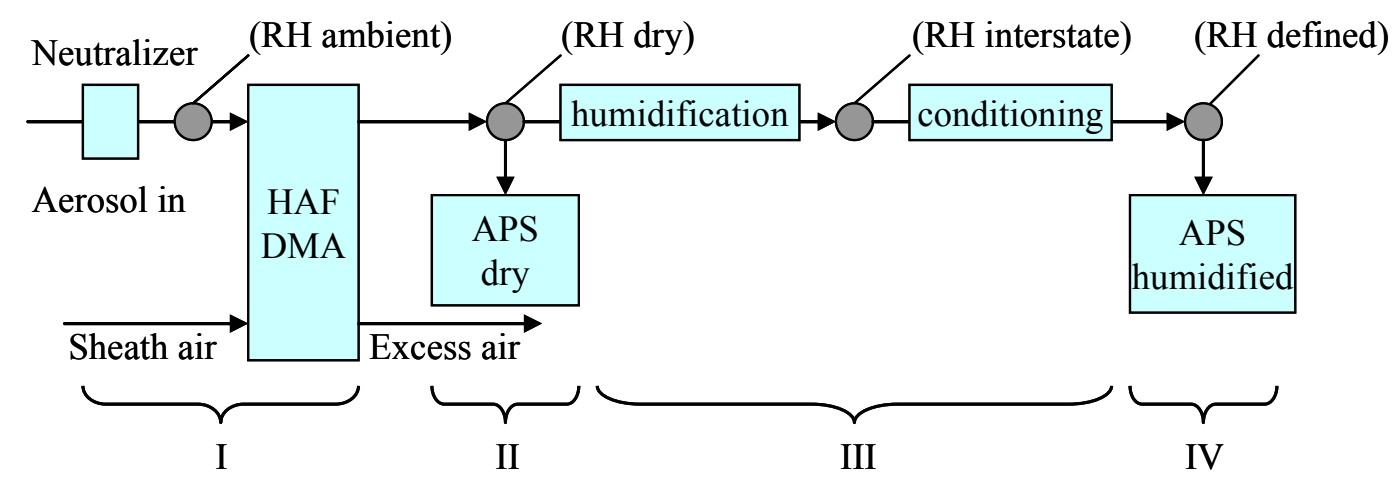

Fig. 2b. Schematic drawing of the H-DMA-APS system.

flow of the sheath air is ten times greater than the monodisperse aerosol flow. The particles take up water depending on their hygroscopicity or chemical composition. The equilibrium size distribution of the humidified aerosol particles is finally measured by the second DMA and a second CPC acting as a mobility size spectrometer (III).

Because the particle number size distribution measured by a DMA is not the true size distribution, but is a convolution of the mobility size distribution with the DMA transfer function and Boltzman-Fuchs charge distribution, an algorithm was applied to recalculate the data. This algorithm developed by Voutilainen et al. (2000) only recalculates the data for single charging and only considers the DMA transfer function of the second DMA. Thus, the size distribution upstream of DMA 2 based on a single charge correction is obtained.

The result of an H-TDMA-scan is a hygroscopic growth distribution in which the particles within a selected diameter interval are classified into groups according to their hygroscopic behavior. These groups appear at different growth factors in the hygroscopic growth distributions depending on their chemical composition. Thus, the results also provide quantitative values of the aerosol's internal, external mixing state in terms of hygroscopicity.

During ACE-Asia, hygroscopic growth distributions were measured for particles with initial dry sizes of $D p=50,150$, 250, and $350 \mathrm{~nm}$ at $90 \% \mathrm{RH}$. Hygroscopic growth distributions for the same values of parameters $(D p, \mathrm{RH})$ were averaged over the time periods given in Table 1 above. The averaged distributions clearly showed modes or groupings of particles according to their different growth factors, i.e., hygroscopic behavior. Log-normal distributions were fitted to the data to describe the different hygroscopic groups. The parameters derived from the H-TDMA growth distributions are: 1) the hygroscopic growth factors, $g f_{i}$, of mode $i$ defined by the ratio of the wet to the dry particle number mean diameter (Eq. 1)

$g f_{i}=\frac{D p_{i, \mathrm{wet}}}{D p_{\mathrm{dry}}}$ and 2) the number fractions, $n f_{i}$, defined by the ratio of the number concentration of particles in each hygroscopicity group, $N_{i}$, and the sum of all observed particles (Eq. 2)

$n f_{i}=\frac{N_{i}}{\sum_{k=1}^{n} N_{k}}$.

The uncertainty of the measurements mainly depends on the uncertainty in RH within the system and possible sizing differences between the two DMAs. In this study, the specific DMAs used were calibrated before the experiment and all data presented here were corrected for observed sizing differences. The RH uncertainty was determined by atomizing sodium chloride particles with an initial dry size of $150 \mathrm{~nm}$ at regular intervals during the campaign, and comparing their hygroscopic growth at a given RH with theory. The calibration revealed that the system $\mathrm{RH}$ was stable within $\pm 3 \% \mathrm{RH}$ over the duration of the cruise. For the data analysis in this work, only spectra taken with an accuracy of $\pm 2 \%$ in $\mathrm{RH}$ were used. The maximum relative uncertainty in hygroscopic growth for a hygroscopic particle (sodium chloride, ammonium sulfate, sodium nitrate, or ammonium nitrate) at $90 \% \pm 2 \% \mathrm{RH}$ is about $\pm 8 \%$. Because most particle fractions of the presented data were less hygroscopic than these pure salt particles, the relative uncertainty of any growth factor measurement was estimated to be less than $8 \%$.

\subsubsection{H-DMA-APS system (Hygroscopicity-Differential Mobility Analyzer-Aerodynamic Particle Sizer)}

The H-DMA-APS is a new system for measurements of hygroscopic properties of aerosol particles at or near $1 \mu \mathrm{m}$ in dry diameter. The system is based on the comparison of measured particle diameter in dry and humidified state by two Aerodynamic Particle Sizers (APS). A schematic of the system is shown in Fig. 2b. Again this system is best described by sections. First, particles in a given Stokes equivalent diameter interval are selected by means of a High Aerosol Flow-Differential Mobility Analyzer (HAF-DMA) in a dry 
state (I). The aerosol flow from the DMA is then split in two fractions. One half of the aerosol flow is directed to the first APS, which characterizes the aerodynamic equivalent diameter of the selected aerosol particles in their dry state at low RH (II). The second half of the aerosol flow is humidified to a defined, higher RH and conditioned to a defined final RH (III). The second APS measures the final size distribution of the selected aerosol at higher RH (IV). The sheath air of this APS is also humidified to the same RH as the conditioned aerosol flow. Humidification and conditioning are accomplished by use of nafion water vapor exchangers. At the intermediate state, the particles can be humidified to about $90 \%$ RH or dried to about $10 \%$ RH before being conditioned to a selected relative humidity. This procedure allows measurement of hygroscopic growth on both branches of a possible hysteresis curve.

The differences in the H-TDMA technique that allow measurement of hygroscopic growth of particles around $1 \mu \mathrm{m}$ in dry diameter, are:

1. use of a custom DMA for the selection of onemicrometer particles with an aerosol flow rate of $2 \mathrm{lpm}$, and a ratio of the aerosol to sheath air flow rate of $1: 10$,

2. use of two APS as detectors instead of a second DMA and $\mathrm{CPC}$,

3. measurement of the dry and hydrated aerodynamic size distribution after the DMA.

The comparison of the particle diameters measured in dry and hydrated states with the two APS units yields the aerodynamic growth factor, $g f_{\text {aero }}$.

During ACE-Asia, particles with an initial dry size of $D p=1 \mu \mathrm{m}$ were selected in the DMA, and subsequently sized at $30 \%$ and at $90 \%$ RH using the second APS unit. The measurement RH was changed periodically, with individual measurements at a specific RH lasting for $15 \mathrm{~min}$. The first APS unit, measuring the size distribution of the particles selected by the HAF-DMA in their dry state, showed sizing problems during this campaign. Therefore, the growth factor was calculated by using the measurements from the second APS unit alone, by comparing the aerodynamic particle size measured at $90 \% \mathrm{RH}$ to the one measured at $30 \% \mathrm{RH}$ using the following Eq. (3):

$g f_{\text {aero }, i}=\frac{D p_{\text {aero }, i, \text { wet }}}{D p_{\text {aero, dry }}}$.

Because the particle concentrations in the coarse particle mode were very low, humidified size distributions for the same values of $(D p, \mathrm{RH})$ were averaged for the time periods to yield one average distribution for the dry state and one for humidified state for each air mass type. The particles in the humidified size distribution appeared in groups according to their differing hygroscopic properties. The averaged size distributions were fitted with log-normal functions to determine the aerodynamic growth factors of different hygroscopic growth groups and their corresponding number fractions via Eq. (2). The APS provides an aerodynamic particle number size distribution and an inversion algorithm is not needed. Doubly charged particles leaving the HAF-DMA could clearly be identified in the data analysis.

The uncertainty in the RH measurement is given as $\pm 1 \% \mathrm{RH}$ in the range up to $90 \% \mathrm{RH}$, and $\pm 2 \%$ for $90 \%$ and above from the manufacturer. The RH control feedback maintained the relative humidity, as measured with the RH sensor, to within $\pm 0.2 \%$ RH of the set point relative humidity. For this system, as for the H-TDMA, the relative uncertainty for the aerodynamic growth factor was estimated to be smaller than $8 \%$ considering the hygroscopic growth factor of a pure sodium chloride particle measured at $90 \% \pm 2 \% \mathrm{RH}$.

For comparison with H-TDMA measurements, the aerodynamic growth factor was converted to a growth factor based on the Stokes diameter using Eq. (4):

$g f_{\text {Stokes }}=g f_{\text {aero }} \times \sqrt{\frac{\rho_{\text {dry }}}{\rho_{\text {wet }}}}$.

Here, the wet density $\rho_{\text {wet }}$ is a function of the growth factor $g f_{\text {Stokes. }}$ Therefore, this equation has to be solved iteratively. For this purpose, the dry density $\rho_{\text {dry }}$ of dry particle needs to be known. The bulk density $\rho$ was determined by Quinn et al. (2004) by gravimetric and chemical analysis for the defined time periods and the selected size range. Because of uncertainties, calculations of the Stokes equivalent growth factor for nearly hydrophobic particles were sometimes less than 1.0. Calculated Stokes equivalent growth factors that undershot this value were set to 1 . This value has to be treated as qualitative, i.e., that no growth was observed within experimental uncertainty. In contrast to this, the number fraction of nearly hydrophobic one-micrometer particles is a quantitative value and can be calculated as defined above.

\section{Results and discussion}

In the following section hygroscopic growth distributions, derived growth factors of particles of different hygroscopic behavior and their corresponding number fractions, all at $90 \% \mathrm{RH}$, are presented and discussed as a function of dry particle size and air mass type. A range of hygroscopic behavior was observed for the particles encountered depending on their size and also within a size class depending on their chemistry and external mixing. Particles exhibiting only small growth factors around 1.1 are called "nearly hydrophobic". Particle groups with growth factors much smaller than ammonium sulfate (around 1.2 to 1.5) are classified as "less hygroscopic". Particles with growth factors close to that of ammonium sulfate (around 1.6 to 1.8) are called "more hygroscopic". A fourth group of particles showing growth 

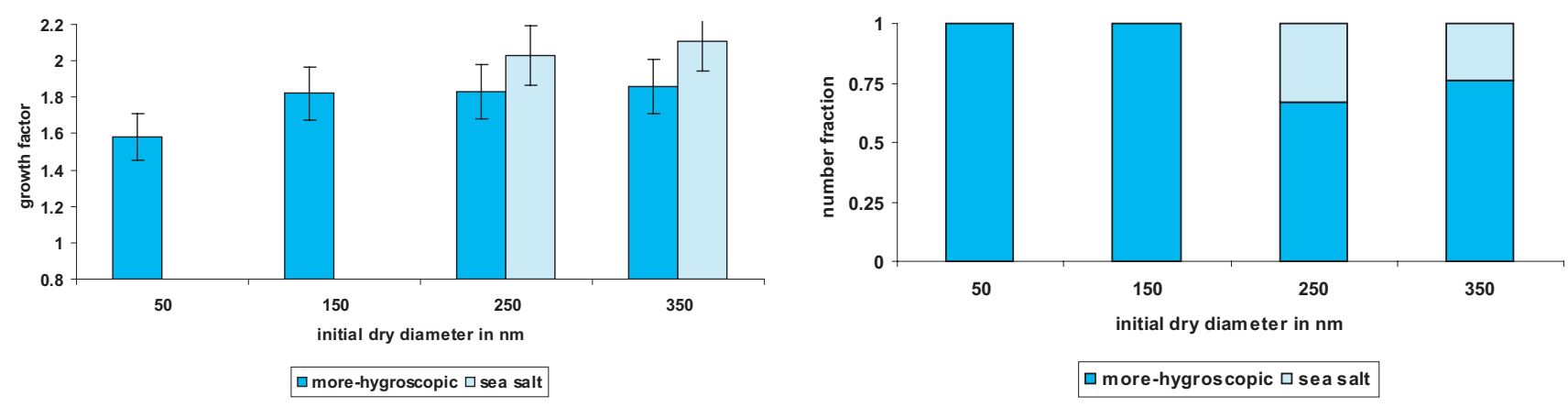

Fig. 3. (a) Hygroscopic growth factors and (b) number fractions for particles with initial dry sizes $D p=50,150,250,350 \mathrm{~nm}$ and $1 \mu \mathrm{m}$ measured at $90 \%$ RH in a clean marine air mass during sampling period 1 . The error bars indicate the accuracy of the reported values.

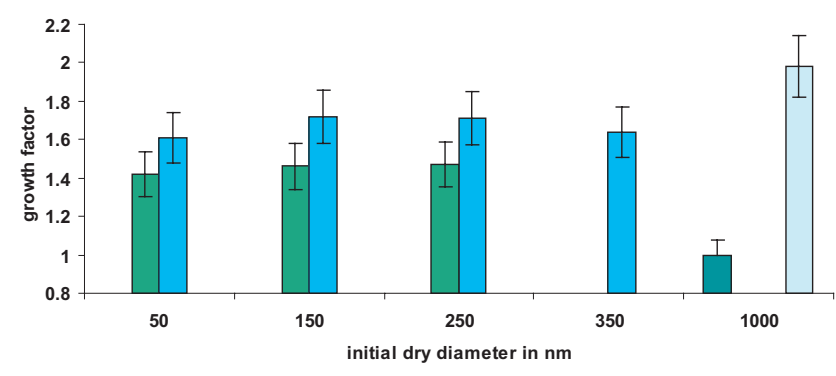

$\square$ nearly-hydrophobic $\square$ less-hygroscopic $\square$ more-hygroscopic $\square$ sea salt

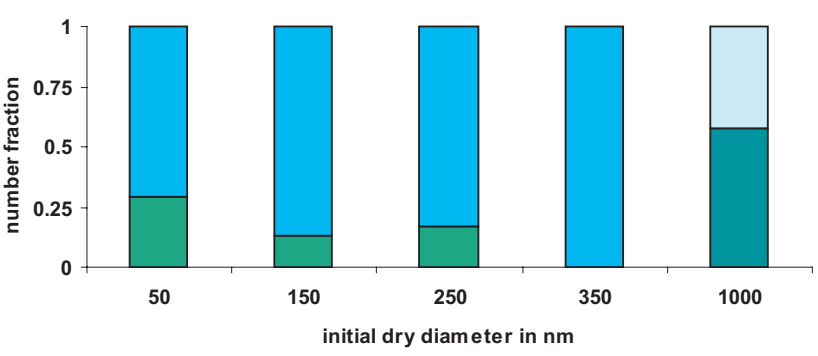

$\square$ nearly-hydrophobic $\square$ less-hygroscopic $\square$ more-hygros copic $\square$ sea salt

Fig. 4. (a, b) As in Fig. 3 for sampling during period 2 in an air mass with pollution sources from Korea/Japan.

factors around 2.0 are categorized as sea salt particles or particles composed of sulfuric acid depending on air mass type.

Because hygroscopic properties of aerosols are dependent primarily on their chemical composition, composition and growth factor must be consistent. To the extent possible we present the observed growth factors and number fractions in the context of inferred compositions or aerosol types and the available, sampling period averaged chemical analysis. The growth distributions extend the size dependent, but still bulk averaged, chemical analysis with information about the degree of mixing within sub-modal size ranges.

In Figs. 3a and b, hygroscopic growth factors and their number fractions for aerosol in a clean, marine air mass (period 1) for particles with initial dry sizes of 50, 150, 250, and $350 \mathrm{~nm}$ are presented. Calculated boundary layer, backtrajectories show that the observed air mass had no land contact during the five previous days (Bates et al., 2004). For all particles in the sub-micrometer size range, a more hygroscopic particle group was found. Within experimental uncertainty, growth factors corresponded to those of ammonium sulfate or partially-neutralized sulfate particles. Quinn et al. (2004) found via impactor measurements that the neutralization ratio of non sea salt sulfate for the sub-micrometer aerosol during this time period was less than $80 \%$. The growth factors for specific diameters were $1.58(50 \mathrm{~nm}), 1.82$
$(150 \mathrm{~nm}), 1.83(250 \mathrm{~nm})$, and $1.86(350 \mathrm{~nm})$, which correspond well to the results of Swietlicki et al. (2000) for a clean marine aerosol in air masses over the Eastern North Atlantic, where hygroscopic growth factors of $1.64(50 \mathrm{~nm})$, $1.77(150 \mathrm{~nm})$, and $1.80(250 \mathrm{~nm})$ were observed during the Second Aerosol Characterization Experiment. Massling et al. (2003) found growth factors of $1.7(50 \mathrm{~nm}), 1.90$ $(150 \mathrm{~nm})$, and $1.93(250 \mathrm{~nm})$ for a clean marine aerosol in air masses in the Indian Ocean during INDOEX that were consistent with a partially-neutralized sulfate aerosol. Particles with initial dry diameters of 250 and $350 \mathrm{~nm}$ divided into a more hygroscopic particle group and a sea salt particle group that showed growth factors greater than 2.0. The number fraction of the sea salt particles was less than $35 \%$ indicating that most particles in this size range can be assigned to ammonium sulfate. For one-micrometer particles, no data were available for the marine case.

Measurements in the air mass, which was strongly influenced by Korean and Japanese sources (period 2), are presented in Figs. 4a and b. During this time period, the ship was located southeast of the Japanese island of Honshu. The back trajectory analysis for this air mass shows that the sampled air masses passed first over Korea and then Japan before reaching the ship's location. The transport time of the observed air masses from these sources to the ship was about 

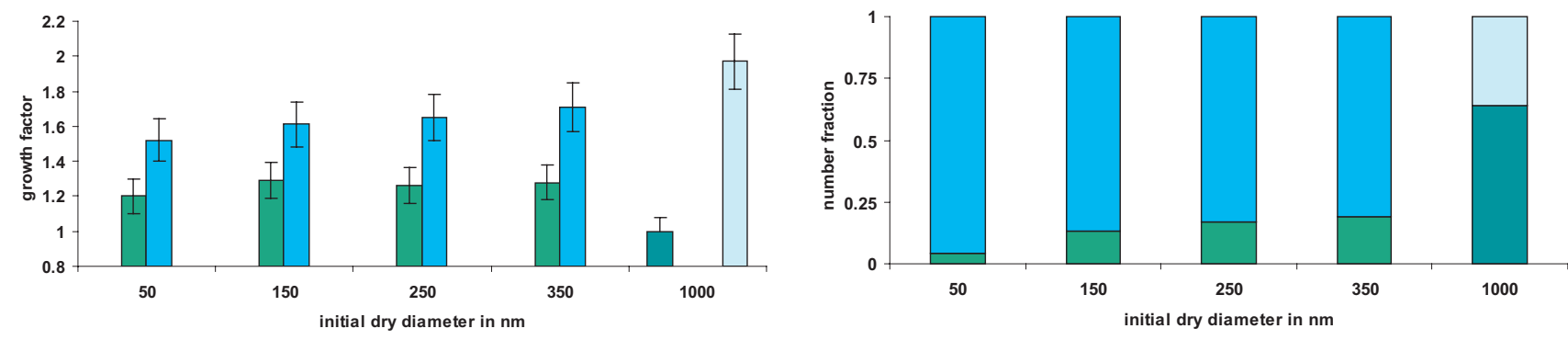

$\square$ nearly-hydrophobic $\square$ less-hygroscopic $\square$ more-hygroscopic $\square$ sea salt

$\square$ nearly-hydrophobic $\square$ less-hygroscopic $\square$ more-hygroscopic $\square$ sea salt

Fig. 5. (a, b) As in Fig. 3 for sampling during period 3 in an air mass with pollution sources from Japan.

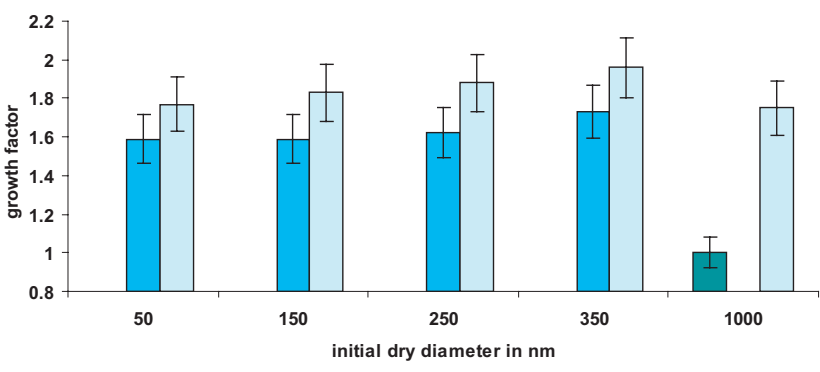

$\square$ nearly-hydrophobic $\square$ more-hygroscopic $\square$ sea salt or sulfate

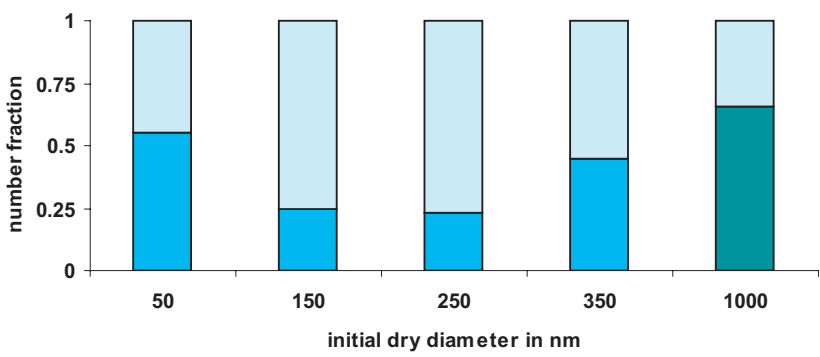

$\square$ nearly-hydrophobic $\square$ more-hygroscopic $\square$ sea salt or sulfate

Fig. 6. (a, b) As in Fig. 3 for sampling during period 4 in an air mass that advected across Miyakejima volcano and Japan to the ship.

24 to $48 \mathrm{~h}$. The figure shows growth factors and number fractions for particles with initial dry sizes of 50, 150, 250, $350 \mathrm{~nm}$, and $1 \mu \mathrm{m}$. In general, a more hygroscopic particle group was observed for all sizes of measured sub-micrometer particles with growth factors similar to those measured during the clean marine period. However, for particles of 150 , 250 , and $350 \mathrm{~nm}$, a less hygroscopic particle group was also present. For the former group, growth factors ranged between 1.4 and 1.5 and number fractions varied between 15 and $30 \%$ depending on the initial size. The latter group is assumed to consist of combustion related particles with sources over Korea and Japan. Their slight hygroscopic growth can be attributed to modifications by condensation from the gas phase or liquid phase processes during transport. These particles might be a mixture of elemental carbon and organic material coated by soluble inorganic or organic substances. Massling et al. (2003) found similar values for less hygroscopic particles when investigating an air mass in the Indian Ocean influenced by sources from the Indian subcontinent during INDOEX. They found growth factors between 1.5 and 1.6 for less hygroscopic particles with number fractions between 35 and $40 \%$. Also, a more hygroscopic and a small nearly hydrophobic particle group were evident. It should be noted here that Quinn et al. (2004) found only very small amounts of nitrate via impactor measurements for this ACE Asia time period in the sub-micrometer size range.
For one-micrometer particles, a nearly hydrophobic particle group occurred that can be attributed to dust particles from continental sources, which are known to be mainly hydrophobic. The number fraction of these particles was found to be approximately $64 \%$. The remaining fraction of the second particle group showed a calculated Stokes diameter growth factor of 1.97. Based on this high value of hygroscopic growth, these particles are strongly suspected to be largely composed of sea salt material.

In Figs. 5a and b, hygroscopic growth factors and their number fractions are presented for an air mass which was highly influenced by emission sources in Japan and reached the ship's location after 6 to $12 \mathrm{~h}$ (Table 1: period 3). During this period, the boundary layer depth decreased from about $1 \mathrm{~km}$ to less than $500 \mathrm{~m}$ and low level back trajectories (100 $500 \mathrm{~m}$ ) showed the air circulating over Japan for several days. In general, hygroscopic behavior similar to that of the continental air mass influenced by Korea and Japan (period 2) was found. In addition to the occurrence of a more hygroscopic particle group, a less hygroscopic particle group with growth factors smaller than those of ammonium sulfate appeared for all sub-micrometer sizes. Here it is noticeable that growth factors of this particle group with values of 1.2 to 1.3 were slightly smaller than those of the corresponding group of the air mass influenced by Korea and Japan. This finding can be explained by different aging times and residence 

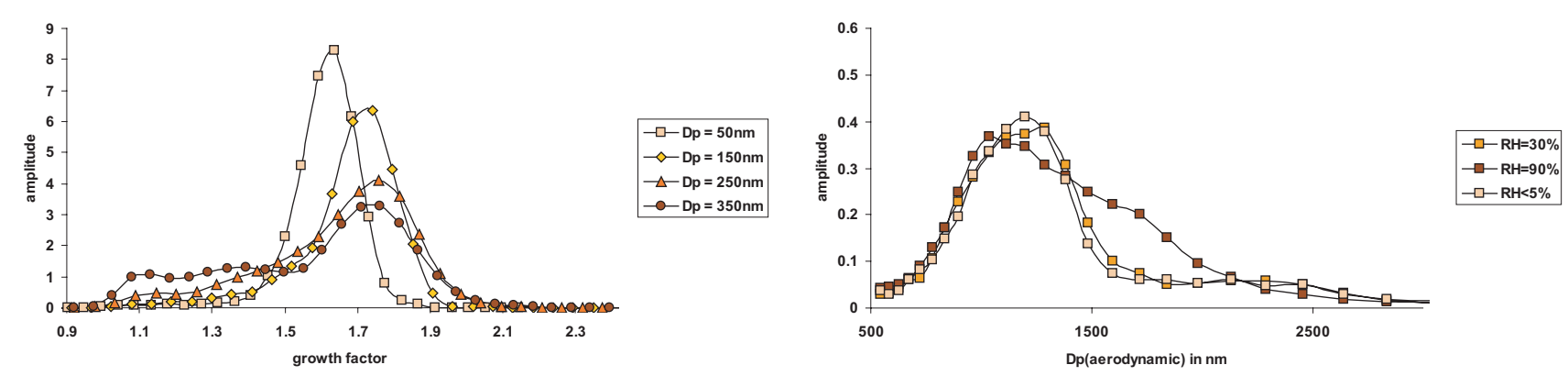

Fig. 7. Hygroscopic growth distributions from (a) the H-TDMA for particles with initial dry sizes $D p=50,150,250$ and $350 \mathrm{~nm}$ and (b) from the H-DMA-APS for particles with an initial dry size $D p=1 \mu \mathrm{m}$ measured at 90,30 , and $<5 \%$ RH for an air mass continentally influenced by Asian dust regions and Shanghai during ACE-Asia. The growth distributions are averaged over the whole sampling period.

times of both air mass types over the continent. Based on air mass back trajectory analysis, the processing time for the air mass encountered during period 2 was longer, 24 to $48 \mathrm{~h}$, than for the air mass during period 3,6 to $12 \mathrm{~h}$, resulting in a slightly greater growth factor for the less hygroscopic particle group during period 2. A second possible explanation could be different emission ratios of less and non hygroscopic compounds to more hygroscopic compounds or their precursors contributing to the particulate matter mix during the two periods.

Also, for the one-micrometer particles two distinct groups of particles, one corresponding to sea salt aerosol and one nearly hydrophobic corresponding to dust aerosol was found.

In Figs. $6 a$ and $b$, growth factors and number fractions are illustrated for the air mass that crossed the Miyakejima volcano and Japan (period 4). During this period, the boundary layer was stable and less than $500 \mathrm{~m}$ in depth. No precipitation was observed and the low level back trajectories (100$500 \mathrm{~m}$ ) clearly showed flow over the volcano (Bates et al., 2003). The hygroscopic properties look very similar to the marine case. For sub-micrometer aerosols, a more hygroscopic particle group was found for all dry sizes. Growth factors were in the range between 1.59 and 1.73. Based on these values it can be assumed that these particles were mainly composed of ammonium sulfate. Additionally, this aerosol is characterized by the appearance of a second particle group with a growth factor slightly larger than the first (1.77 to 1.96). Volcanoes are a significant emission source for $\mathrm{SO}_{2}$, which typically is oxidized in the atmosphere to sulfuric acid vapor. High concentrations of sulfuric acid intensify the formation of particles composed of sulfate and also enable the mass transfer of sulfate on existing particles. These processes lead to a hygroscopic particle population mainly composed of sulfate or partially-neutralized sulfate particles and are a simple explanation for the appearance of this more hygroscopic particle group. This aerosol will be neutralized by further aging processes. Also, Quinn et al. (2004) found a neutralization ratio less than $50 \%$ for non sea salt sulfate during this time period in the sub-micrometer size range. The fact that these particles were observed in all size classes during period 4 but only in the largest size classes during other periods supports the dominance of sulfate particles in this group. However, the presence of sea salt in the more hygroscopic group can not be excluded because the hygroscopic growth of sea salt and sulfuric acid particles is nearly the same.

The hygroscopic growth distribution of one-micrometer particles shows a split into two groups of different hygroscopic behavior. Again, a nearly hydrophobic group of aerosol particles is observed with a number fraction of $66 \%$. The second group of more hygroscopic particles shows a calculated growth factor (Stokes diameter) of 1.75, which indicates ammonium sulfate as main compound. Also, the large fraction of sulfate can be explained by volcano emissions in this size range. One explanation for the fully-neutralized sulfate particles here could be the higher probability for onemicrometer particles for cloud processing leading to higher neutralization ratios.

In Fig. 7a, examples of averaged hygroscopic growth distributions measured at $90 \% \mathrm{RH}$ for sub-micrometer aerosol particles are presented for period 5 when the ship was sampling in the Korean Strait and the trajectory analysis shows the air masses coming from Northern China and Mongolian dust regions before they passed over Shanghai to reach the ship's location. The H-TDMA growth distributions split into different groups of hygroscopic behavior. Nearly hydrophobic particles, $g f$ ca. 1.1 and linked to dust, only occurred for larger sizes $(D p=250$ and $350 \mathrm{~nm})$. For comparison, the hygroscopic growth distributions of one-micrometer particles from the H-DMA-APS are presented in Fig. 7b for this air mass type taken at dry conditions $(<5 \% \mathrm{RH})$, at $30 \% \mathrm{RH}$, and at $90 \%$ RH. The distribution taken at dry conditions only shows one major group of particles at about 1.2 to $1.3 \mu \mathrm{m}$ in aerodynamic diameter. A second mode at greater diameters can be assigned to doubly-charged particles from the DMA. The distribution taken at 30\% RH shows a small growth shift towards larger sizes. Data taken at $90 \% \mathrm{RH}$ show a split into two groups with different hygroscopic growth. One group 


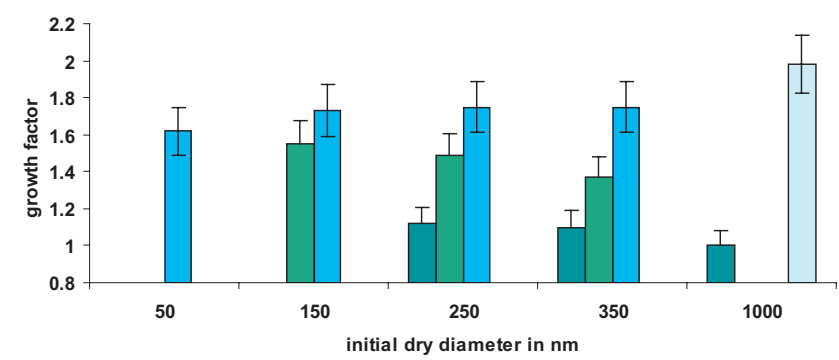

nearly-hydrophobic $\square$ less-hygroscopic $\square$ more-hygroscopic $\square$ sea salt

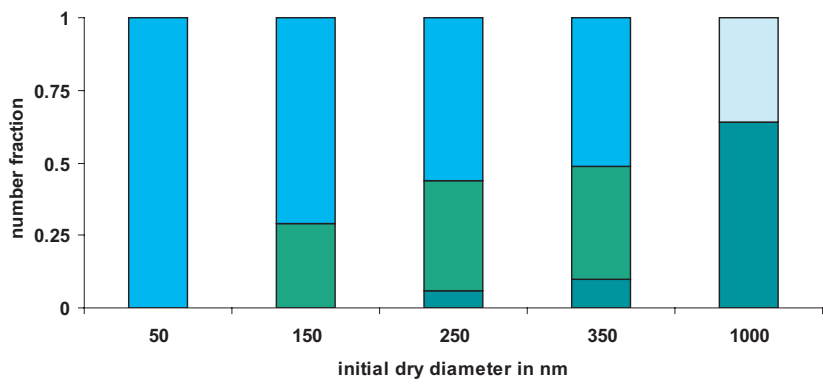

$\square$ nearly-hydrophobic $\square$ less-hygroscopic $\square$ more-hygroscopic $\square$ sea salt

Fig. 8. (a, b) As in Fig. 3 for sampling during period 5 in an air mass influenced by sources from Asian dust regions and Shanghai.

shows no growth in comparison to $30 \% \mathrm{RH}$ and the other one shows a significant growth towards larger diameters. The latter group can be assigned to sea salt particles, which are known to be very hygroscopic. The first group can be attributed to dust particles, which are known to be hydrophobic. This number fraction of the latter particles is greatly increased compared to those found in the sub-micrometer size range because dust particles have their maximum of emission at diameters $D p \geq 1 \mu \mathrm{m}$.

In Figs. 8a and b, growth factors and their number fractions are illustrated for the air mass discussed above. Here, the sub-micrometer aerosol always showed a dominant, more hygroscopic particle group with growth factors between 1.62 and 1.75 . For $50 \mathrm{~nm}$ particles, this was the only observed group. Accumulation mode particles were subdivided into a less hygroscopic particle group with growth factors slightly smaller than those of ammonium sulfate as was the case for other continentally air masses discussed before. The observed hygroscopic growth factors for these particles varied between 1.37 and 1.55 with number fractions between 30 and $40 \%$ and the particles can be assigned to anthropogenic aerosols, which were modified by condensation from the gas phase or liquid phase processes. Additionally, a small number fraction (6\% and $10 \%$, respectively) of nearly hydrophobic particles occurred for the 250 and $350 \mathrm{~nm}$ particles. This group indicates the presence of submicrometric dust particles that were mixed into the air mass when it passed over the Asian dust source regions. Dust particles are not expected to extend to the Aitken mode size range.

With regard to the one-micrometer particles, a sea salt group with a corresponding growth factor of 1.98 (Stokes diameter) and a number fraction of $36 \%$ was also observed. Nevertheless, the nearly hydrophobic dust particle group also occurred and dominated the number fraction at this particle size.

\section{Summary and conclusions}

During ACE-Asia, an H-TDMA system and an H-DMAAPS system to measure hygroscopic properties of particles in the sub-micrometer and one-micrometer size ranges were deployed on the Research Vessel Ronald H. Brown. The ship started its cruise with a route from Hawaii (USA) to Japan and concluded with legs south and west of Japan and in the Sea of Japan. During this route seven distinct air mass types of different origin were observed, five of which were used in our analysis. At the beginning of the cruise, air masses of marine origin having no land contact for five days were encountered over a period of eleven days. This period was followed by air mass types with continental, anthropogenic influence from Korea and Japan and air masses, which had crossed Asian desert dust regions in Northern China and/or Mongolia.

In general, different hygroscopic behavior of atmospheric particles was observed for the dry sizes $(D p=50,150,250$, $350 \mathrm{~nm}$, and $1 \mu \mathrm{m}$ ) within one air mass type as well as between different air mass types. This result was obtained for measurements done at $90 \%$ RH. This set of results implies that particles of different dry size had varying chemical composition with a high degree of external mixing within a given air mass type.

For all air mass types, a dominant, more hygroscopic particle fraction indicative of ammonium sulfate particles was found for sub-micrometer particles and a fraction indicative of sea salt particles was found for one-micrometer particles. Sea salt particles in the sub-micrometer size range were only identified for $D p=250$ and $350 \mathrm{~nm}$ during the clean marine period.

Less hygroscopic sub-micrometer particles only occurred in those cases when air masses with continental, anthropogenic influence were observed. They are assumed to have their origin in relatively recently emitted aerosol, which was modified during transport from its source to the ship by condensation from the gas phase or liquid phase reactions or by cloud processing resulting in particles showing 
less growth than expected for pure ammonium sulfate particles. This hygroscopic growth group was not observed for one-micrometer particles at all. For sub-micrometer aerosol, number fractions of the less hygroscopic group varied between 10 and 50\% depending on dry particle size.

Additionally, sub-micrometer particles that had a nearly hydrophobic behavior can likely be assigned to freshly emitted soot particles or dust particles, which were only found during one time period when air masses were influenced by Shanghai anthropogenic sources and Asian desert dust regions for larger particle sizes with $D p=250$ and $350 \mathrm{~nm}$. These particles can be inferred to be dust particles that are known to be non-hygroscopic and that were also found in the one-micrometer size regime. One-micrometer dust particles were universally observed in all of the continentally influenced air masses, even for some of which did not show a clear trajectory over the major Asian dust source regions. These observations imply that dust particles seem to be a major constituent of coarse mode particles in this region independent of the air mass imprint. Number fractions of this particle group were about $60 \%$ for one-micrometer particles and all observed air mass types.

Given that a continuous range of growth factors is possible, it is noteworthy that for each dry size, the modal growth factors for the four groups were highly constant within each sampling period and further that the inter-sample variability of the modal values for this and previous H-TDMA data sets is also small compared to the overall range of observed growth factors.

\section{Appendix A}

The Appendix Tables include numeric values of growth factors and number fractions for different dry sizes for each sampling period, air mass type. The growth factors 1 through 4 are assigned to: nearly hydrophobic, less hygroscopic, more hygroscopic, and sea salt particle groups, respectively, as determined by the H-TDMA hygroscopic growth distributions.

Table A1. Growth factors and corresponding number fractions for particles of different size measured at $90 \% \mathrm{RH}$ (marine air mass, period 1). The maximum relative uncertainty of growth factors is less than $8 \%$. The relative uncertainty of number fractions is estimated to be smaller than $5 \%$.

\begin{tabular}{lllllllll}
\hline$D p[\mathrm{~nm}]$ & $g f_{-} 1$ & $g f_{-} 2$ & $g f_{-} 3$ & $g f_{-} 4$ & $n f_{-} 1$ & $n f_{-} 2$ & $n f_{-} 3$ & $n f_{-} 4$ \\
\hline 50 & - & - & 1.58 & - & - & - & 1 & - \\
150 & - & - & 1.82 & - & - & - & 1 & - \\
250 & - & - & 1.83 & 2.03 & - & - & 0.67 & 0.33 \\
350 & - & - & 1.86 & 2.11 & - & - & 0.76 & 0.24 \\
\hline
\end{tabular}

Table A2. Growth factors and corresponding number fractions for particles of different size measured at $90 \%$ RH (pollution from Korea/Japan, period 2).

\begin{tabular}{lllllllll}
\hline$D p[\mathrm{~nm}]$ & $g f_{-} 1$ & $g f_{-} 2$ & $g f_{-} 3$ & $g f_{-} 4$ & $n f_{-} 1$ & $n f_{-} 2$ & $n f_{-} 3$ & $n f_{-} 4$ \\
\hline 50 & - & 1.42 & 1.61 & - & - & 0.29 & 0.71 & - \\
150 & - & 1.46 & 1.72 & - & - & 0.13 & 0.87 & - \\
250 & - & 1.47 & 1.71 & - & - & 0.17 & 0.83 & - \\
350 & - & - & 1.64 & - & - & - & 1 & - \\
\hline
\end{tabular}

Table A3. Growth factors and corresponding number fractions for particles of different size measured at $90 \% \mathrm{RH}$ (pollution from Japan, period 3).

\begin{tabular}{lllllllll}
\hline$D p[\mathrm{~nm}]$ & $g f_{-} 1$ & $g f_{-} 2$ & $g f_{-} 3$ & $g f_{-} 4$ & $n f_{-} 1$ & $n f_{-2}$ & $n f_{-} 3$ & $n f_{-} 4$ \\
\hline 50 & - & 1.20 & 1.52 & - & - & 0.04 & 0.96 & - \\
150 & - & 1.29 & 1.61 & - & - & 0.13 & 0.87 & - \\
250 & - & 1.26 & 1.65 & - & - & 0.17 & 0.83 & - \\
350 & - & 1.28 & 1.71 & - & - & 0.19 & 0.81 & - \\
\hline
\end{tabular}

Table A4. Growth factors and corresponding number fractions for particles of different size measured at $90 \% \mathrm{RH}$ (volcano imprinting, period 4).

\begin{tabular}{lllllllll}
\hline$D p[\mathrm{~nm}]$ & $g f_{-} l$ & $g f_{-} 2$ & $g f_{-} 3$ & $g f_{-} 4$ & $n f_{-} 1$ & $n f_{-}$ & $n f_{-} 3$ & $n f_{-} 4$ \\
\hline 50 & - & - & 1.59 & 1.77 & - & - & 0.55 & 0.45 \\
150 & - & - & 1.59 & 1.83 & - & - & 0.25 & 0.75 \\
250 & - & - & 1.62 & 1.88 & - & - & 0.23 & 0.77 \\
350 & - & - & 1.73 & 1.96 & - & - & 0.45 & 0.55 \\
\hline
\end{tabular}

Table A5. Growth factors and corresponding number fractions for particles of different size measured at $90 \% \mathrm{RH}$ (pollution from Shanghai and dust, period 5).

\begin{tabular}{lllllllll}
\hline$D p[\mathrm{~nm}]$ & $g f_{-} 1$ & $g f_{-} 2$ & $g f_{-} 3$ & $g f_{-} 4$ & $n f_{-} 1$ & $n f_{-} 2$ & $n f_{-} 3$ & $n f_{-} 4$ \\
\hline 50 & - & - & 1.62 & - & - & - & 1 & - \\
150 & - & 1.55 & 1.73 & - & - & 0.29 & 0.71 & - \\
250 & 1.12 & 1.49 & 1.75 & - & 0.06 & 0.38 & 0.56 & - \\
350 & 1.10 & 1.37 & 1.75 & - & 0.10 & 0.39 & 0.51 & - \\
\hline
\end{tabular}


Table A6. Growth factors, corresponding number fractions and densities for ca. $1 \mu \mathrm{m}$ diameter particles of different air mass origin measured at $90 \% \mathrm{RH}$ by the H-DMA-APS.

\begin{tabular}{|c|c|c|c|c|c|c|c|c|c|c|}
\hline Air mass & $\rho$ & $g f$ aero_1 & $n f \_1$ & $g f$ Stokes_1 & $g f$ aero $\_3$ & $n f \_3$ & $g f$ Stokes_3 & $g f$ aero_4 & $n f \_4$ & $g f$ Stokes_4 \\
\hline Polluted Japan (3) & 1.91 & 0.95 & 0.64 & $(1.00)$ & - & - & - & 1.51 & 0.36 & 1.97 \\
\hline Dust + Shanghai (5) & 2.36 & 0.92 & 0.64 & $(1.00)$ & - & - & - & 1.40 & 0.36 & 1.98 \\
\hline
\end{tabular}

Acknowledgements. We are grateful for the support and cooperation of the NOAA PMEL group, who gave us the opportunity to participate in this field study. We also thank the officers and crew of the Ronald H. Brown and participants of the cruise from the University of Washington and PMEL for the excellent and effective teamwork and brilliant scientific guidance during the cruise.

Edited by: A. Petzold

\section{References}

Bates, T., Quinn, P., Coffman, D., Covert, D., Miller, T., Johnson, J., Carmichael, G., Guazzotti, S., Sodeman, D., Prather, K., Rivera, M., Russell, L., and Merrill, J.: Marine boundary layer dust and pollutant transport associated with the passage of a frontal system over eastern Asia, J. Geophys. Res., 109(D19), D19S19, doi:10.1029/2003JD004094, 2003.

Berg, H. O., Swietlicki, E., and Krejci, R.: Hygroscopic growth of aerosol particles in the marine boundary layer over the $\mathrm{Pa}-$ cific and Southern Oceans during the First Aerosol Characterization Experiment (ACE 1), J. Geophys. Res., 103, 16535-16545, 1998.

Charlson, R. J.: Atmospheric visibility related to aerosol mass concentration, Environ. Sci. Technol., 3, 913-918, 1969.

Cooney, C. M.: California moves ahead on diesel exhaust study, Environ. Sci. \& Technol., 32(11), 250A-250A, 1998.

Ferron, G. A., Karg, E., and Peter, J. E.: Estimation of deposition of polydisperse hygroscopic aerosols in the human respiratory tract, J. Aerosol Sci., 24, 655-670, 1998.

Horvath, H.: Estimation of the average visibility in central Europe, Atmos. Environ., 29(2), 241-246, 1995.

Kasten, F.: Der Einfluß der Aerosol-Größenverteilung und ihrer Änderung mit der relativen Feuchte auf die Sichtweite, Contrib. Atmos. Phys., 41, 33-51, 1968.

Liu, B. Y. H., Pui, D. Y. H., Whitby, K. T., Kittelson, D. B., Kousaka, Y., and McKenzie, R. L.: The aerosol mobility chromatograph: a new detector for sulfuric acid aerosols, Atmos. Environ., 12, 99-104, 1978.
Massling, A., Wiedensohler, A., Busch, B., Neusüß, C., Quinn, P., Bates, T., and Covert, D.: Hygroscopic properties of different aerosol types over the Atlantic and Indian Oceans, Atmos. Chem. and Phys., 3, 1377-1397, 2003.

Noll, K. E., Mueller, P. K., and Imada, M.: Visibility and aerosol concentration in urban air, Atmos. Environ., 2, 465-475, 1968.

Ogren, J. A. and Charlson R. J.: Implications for models and measurements of chemical inhomogeneities among cloud droplets, Tellus, 44B, 489-504, 1992.

Peters, A., Wichmann, H. E., Tuch, T., Heinrich, J., and Heyder, J.: Respiratory effects are associated with the number of ultrafine particles, Am. J. Respir. Crit. Care Med., 155, 1376-1383, 1997a.

Peters, A., Wichmann, H. E., Tuch, T., Heinrich, J., and Heyder, J.: Comparison of the number of ultra-fine particles and the mass of fine particles with respiratory symptoms in asthmatics, Ann. Occup. Hyg., 41(1), 19-23, 1997b.

Pope, C. A. I. and Dockery, D. W.: Epidemiology of particle effects, Air Poll. Health, 31, 673-705, 1999.

Quinn, P. K., Coffman, D. J., Bates, T. S., Welton, E. J., Covert, D. S., Miller, T. L., Johnson, J. E., Maria, S., Russell, L., Arimoto, R., Carrico, C. M., Rood, M. J., and Anderson, J.: Aerosol optical properties measured onboard the Ronald $\mathrm{H}$. Brown during ACE Asia as a function of aerosol chemical composition and source region, J. Geophys. Res., 109(D19), D19S01, doi:10.1029/2003JD004010, 2004.

Swietlicki, E., Zhou, J. C., Covert, D. S., Hameri, K., Busch, B., Vakeva, M., Dusek, U., Berg, O. H., Wiedensohler, A., Aalto, P., Makela, J., Martinsson, B. G., Papaspiropoulos, G., Mentes, B., Frank, G., and Stratmann, F.: Hygroscopic properties of aerosol particles in the eastern Northern Atlantic during ACE-2, Tellus, 52B, 201-227, 2000.

Tsay, S.-C., Stephens, J. L., and Greenwald, T. J.: An investigation of aerosol microstructure on visual air quality, Atmos. Environ., 25A, 1039-1053, 1991.

Twomey, S.: Atmospheric aerosols, Elsevier, New York, 1977.

Voutilainen, A., Stratmann, F., and Kaipio, J. P.: A nonhomogenous regularization method for the estimation of narrow aerosol size distribution, J. Aerosol Sci., 31(12), 1433-1445, 2000. 